\title{
Reduction-Triggered Paclitaxel Release Nano-Hybrid System Based on Core-Crosslinked Polymer Dots with a pH-Responsive Shell-Cleavable Colorimetric Biosensor
}

\author{
Seul Gi Kim ${ }^{1}$, Benny Ryplida ${ }^{2}$, Pham Thi My Phuong ${ }^{2}{ }^{\circledR}$, Hyun Jeong Won ${ }^{1}$, Gibaek Lee ${ }^{1}$, \\ Suk Ho Bhang ${ }^{3, *}$ and Sung Young Park $1,2,4, *$ \\ 1 Department of Chemical and Biological Engineering, Korea National University of Transportation, \\ Chungju 380-702, Korea; k.seulgi9797@gmail.com (S.G.K.); dnjsswh@ut.ac.kr (H.J.W.); glee@ut.ac.kr (G.L.) \\ 2 Department of Green Bio Engineering, Korea National University of Transportation, Chungju 380-702, Korea; \\ ryplida@gmail.com (B.R.); ptmp.2411@gmail.com (P.T.M.P.) \\ 3 School of Chemical Engineering, Sungkyunkwan University, Suwon 16419, Korea \\ 4 Department of IT Convergence, Korea National University of Transportation, Chungju 380-702, Korea \\ * Correspondence: sukhobhang@skku.edu (S.H.B.); parkchem@ut.ac.kr (S.Y.P.); Tel.: +82-43-841-5225 (S.H.B.)
}

Received: 2 September 2019; Accepted: 25 October 2019; Published: 28 October 2019

\begin{abstract}
Herein, we describe the fabrication and characterization of carbonized disulfide core-crosslinked polymer dots with $\mathrm{pH}$-cleavable colorimetric nanosensors, based on diol dye-conjugated fluorescent polymer dots (L-PD), for reduction-triggered paclitaxel (PTX) release during fluorescence imaging-guided chemotherapy of tumors. L-PD were loaded with PTX (PTX loaded L-PD), via $\pi-\pi$ stackings or hydrophobic interactions, for selective theragnosis by enhanced release of PTX after the cleavage of disulfide bonds by high concentration of glutathione (GSH) in a tumor. The nano-hybrid system showed fluorescence quenching behavior with less than $2 \%$ of PTX released under physiological conditions. However, in a tumor microenvironment, the fluorescence recovered at an acidic-pH, and PTX (approximately $100 \%$ of the drug release) was released efficiently out of the matrix by reduction caused by the GSH level in the tumor cells, which improved the effectiveness of the cancer treatment. Therefore, the colorimetric nanosensor showed promising potential in distinguishing between normal and cancerous tissues depending on the surrounding $\mathrm{pH}$ and GSH concentrations so that PTX can be selectively delivered into cancer cells for improved cancer diagnosis and chemotherapy.
\end{abstract}

Keywords: nano-hybrid matrix; polymer dots; controllable drug release; $\mathrm{pH}$-sensitive; redox-responsive

\section{Introduction}

Drug delivery innovation has been rapidly advancing, but it requires continuous development to improve therapeutic performance. However, current drug delivery nano-based systems are limited by the need for high dosages, the poor availability of drugs at disease sites, and the unwanted side effects [1]. It is therefore necessary to develop controlled drug delivery with the ability to transport drugs effectively and efficiently to tumor sites [2]. Taking into account the fact that the extracellular microenvironment of tumor tissue is acidic at approximately $\mathrm{pH}$ 6.5-6.9 as compared to normal tissue ( $\mathrm{pH}$ 7.2-7.4) [3], a pH-sensitive nanosystem could be beneficial in distinguishing between tumor and healthy tissues to solve the drawbacks in drug delivery. Additionally, tumor cells contain a reducing substance in the form of glutathione (GSH), which has been proved to be at least four times higher than that in the normal cells $[4,5]$. Considering both facts, a dual $\mathrm{pH}$ and redox-sensitive drug delivery system (DDS) may have great potential for the controlled release of drugs for efficient cancer therapy especially hydrophobic drugs [6]. 
Polymer-based nano-hybrid delivery systems, especially in cancer therapy, have been extensively investigated as a way to achieve temporal and spatial control for targeting drug delivery at disease sites such as lipid based vesicular, micelle-like structure or nanogel-based DDS systems [2,7-11]. However, most of organic compound-based nano-hybrid systems still need to be improved due to a lack of real-time monitoring properties; they also show low drug-loading percentages and poor stability during blood circulation, thus hindering their performance, which remains a noticeable challenge [12]. Recently, $\mathrm{sp}^{2}$-riched carbon hybrid nanocomposites such as graphene oxide (GO) and carbon nanotubes (CNTs) were employed as drug carriers for better stability. However, the nano-based system still showed problems, especially during the drug-release phase [13]. The $\pi-\pi$ stackings and hydrophobic interactions hindered the release of the drug during delivery, making the controlled release of a hydrophobic drug to the desired tumor site difficult [14]. Therefore, a drug nano-hybrid matrix containing both hydrophobic and hydrophilic sides and that has a structure similar to that of graphene would improve the stability and drug release during delivery [15]. In recent times, fluorescent polymer dots (PD) have been studied owing to their nanoparticle size, easy preparation, desirable biocompatibility, and sensitivity to environmental conditions such as $\mathrm{pH}$, redox potential, light, and temperature after modifications [16-18]. PD have been reported to possess a lattice structure similar to that of GO and the ability to form core-shell structures under aqueous conditions due to rich $\mathrm{sp}^{2}$ bonds in the core and hydrophilic segments in the shell, which can be easily loaded with hydrophobic drugs. As compared with conventional systems, PD has performed lower systemic toxicity with prolong drug circulation time that also improved drug solubility and targeting ability. These characteristics suggest that PD could act as stable drug carriers with real-time monitoring properties that would meet the criteria for an intelligent, stimuli-responsive drug carrier.

In this study, we designed a dual-sensitive drug delivery system based on a carbonized form of disulfide-crosslinked pluronic-grafted-2-(dimethylamino) ethyl methacrylate-2-hydroxyethyl methacrylate (B/S-Pluronic) to achieve $\mathrm{pH}$ - and redox-responsive fluorescence $\mathrm{PD}(\mathrm{B}-\mathrm{PD})$. These were then conjugated with fluorescent dyes to form L-PD by utilizing the boron-diol interaction to turn the fluorescence "off", which hypothetically could recover under acidic pH. Next, the L-PD was loaded with paclitaxel (PTX; PTX loaded L-PD) through $\pi-\pi$ stacking or hydrophobic interactions for simultaneous diagnosis and cancer therapy by controlled release of PTX after cleaving disulfide bonds by GSH. It is hypothesized that the designed DDS could show fluorescence quenching behavior at physiological $\mathrm{pH}$ and low drug release amounts without GSH. Oppositely, the fluorescence could be recovered by tumor acidic environment and PTX could be sustainably released from the matrices in a time manner to start therapeutic procedure responded quickly to reductive GSH concentration in the cancer cell to enhance the therapeutic efficacy of anticancer drugs. Therefore, the distinguishing characteristic of the proposed system may be the selectivity of a PTX loaded L-PD system in response to surrounding $\mathrm{pH}$ and GSH concentrations, thus showing its promising potential for an improved cancer diagnosis and therapy.

\section{Results and Discussion}

\subsection{Synthesis and Characterization of PTX Loaded L-PD}

The synthesis method and principle of simultaneous diagnosis and therapy of PTX loaded L-PD are shown in Scheme 1. The matrices were formed by grafting 2-(dimethylamino) ethyl methacrylate (DMA) and 2-hydroxyethyl methacrylate (HEMA) to Pluronic F-127 to obtain B/S-Pluronic (Scheme S1). To achieve structural stability and redox-responsive functional groups, disulfide bonds (-S-S-) were introduced by allowing the polymer matrices to react with cysteamine; the disulfide-crosslinked polymers spontaneously formed within $48 \mathrm{~h}$. Once B-PD was achieved by carbonization using an oxidative reaction with concentrated sulfuric acid $\left(\mathrm{H}_{2} \mathrm{SO}_{4}\right)$, B-PD was conjugated with fluorescent dye (DYE) utilizing boron-diol chemistry to achieve fluorescence quenching and $\mathrm{pH}$-sensitive nanoparticles (L-PD). Paclitaxel (PTX) was then loaded into the nano-hybrid matrices by optimizing the $\pi-\pi$ stackings 
or hydrophobic interactions between the aromatic group of PTX and the $\mathrm{sp}^{2}$ group of the L-PD to form PTX loaded L-PD [19]. In a tumor environment (acidic $\mathrm{pH}$ ), it is expected that the disintegration of boronate ester bonds could recover the fluorescence intensity that would subsequently discharge DYE and facilitate further cleavage of disulfide bonds by high concentrations of GSH, releasing PTX to kill cancer cells [20].
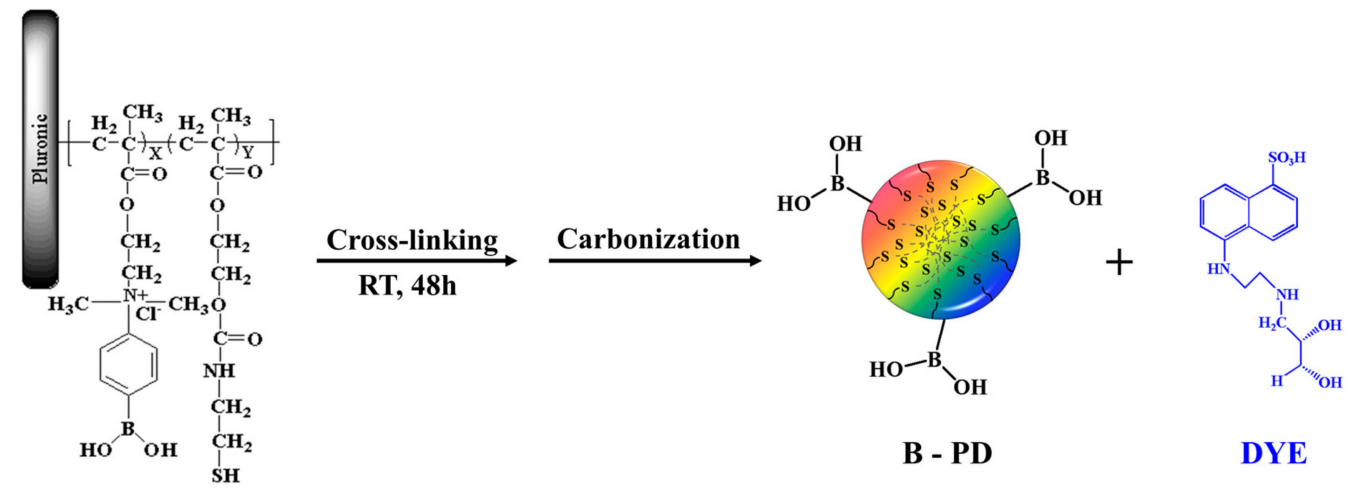

B/S - Pluronic

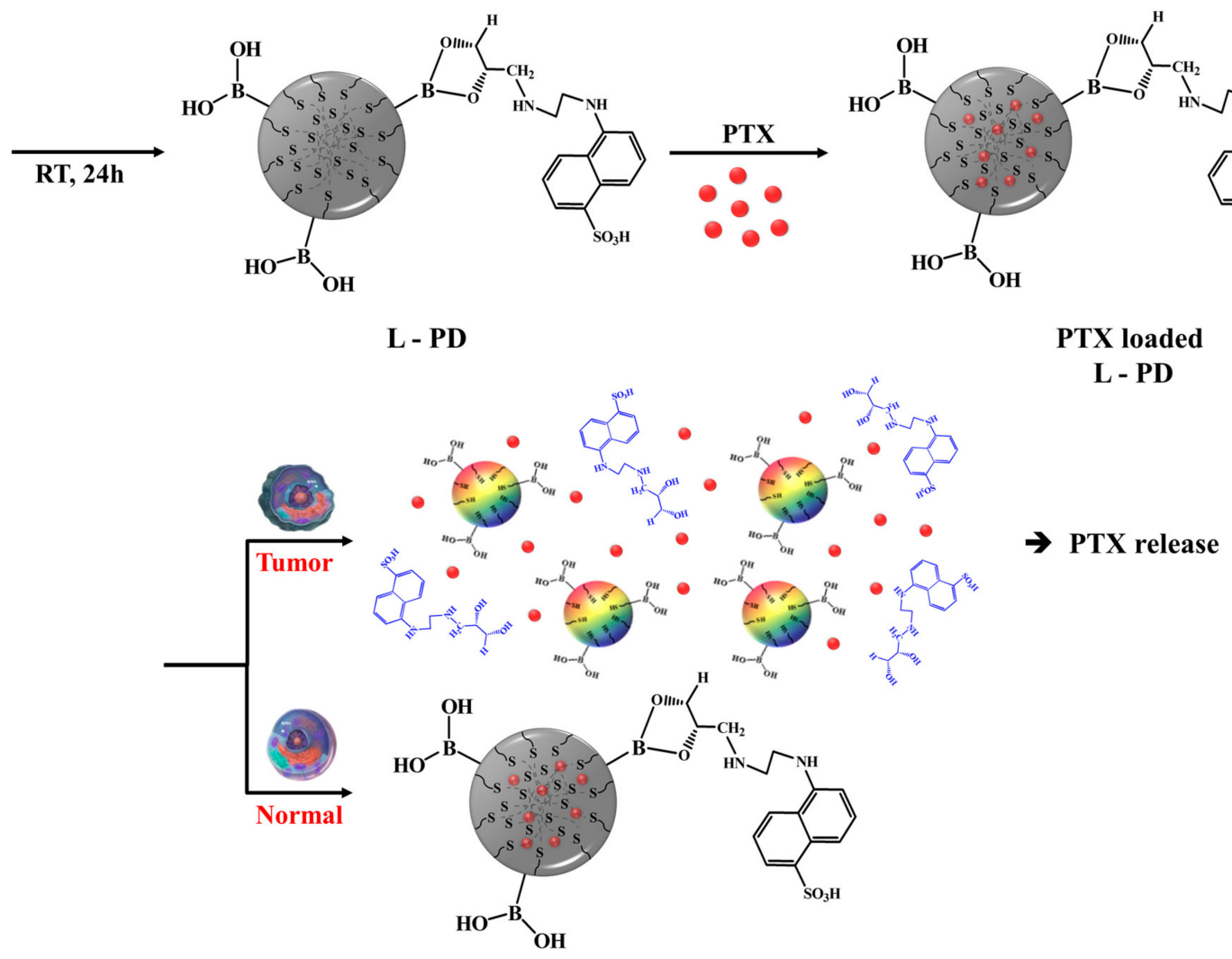

Scheme 1. Illustration of the synthesis of dual pH-redox-responsive PTX loaded diol dye-conjugated fluorescent polymer dot (L-PD) nano-hybrid for fluorescent "OFF/ON" and controlled release of PTX in cancer cells.

The chemical structure of the PTX loaded L-PD nanoparticles was analyzed using FT-IR spectra. As shown in Figure S1, the presence of peak at $1020 \mathrm{~cm}^{-1}$ of B-PD, which is specific to B-O-H functional groups was observed initially, which then disappear after DYE was introduced, indicating successful conjugation of DYE to B-PD (L-PD) [21]. Moreover, UV-vis spectrophotometry was used to confirm the synthesis results of each nanoparticles. As displayed in Figure S2a, the B-PD displayed broad absorbance peaks between $200-300 \mathrm{~nm}$, which represents a typical absorbance range for $s p^{2}$ carbon that 
could act as a fluorophore of the nano-hybrid system [22]. However, the absorbance peak shifted to longer wavelengths after the conjugation with DYE, demonstrating successful attachment of DYE to the B-PD (L-PD). Further confirmation of the conjugation of DYE-PD analysis was obtained using ${ }^{1} \mathrm{H}-\mathrm{NMR}$. As shown in Figure 1a, the conjugation of DYE to the B-PD was observed at 7-9 ppm, corresponding to the aromatic peaks of DYE, confirming attachment of DYE onto the PD shells [23]. Additionally, the surface charge properties during synthesis were investigated (Figure S3). The B/S-Pluronic surface charge was $14.8 \pm 1.3 \mathrm{mV}$, which decreased to $7.5 \pm 0.9 \mathrm{mV}$ after carbonization owing to the presence of carboxylic groups (B-PD). After DYE was introduced, the zeta potentials slightly shifted to $5.1 \pm 0.9 \mathrm{mV}$ due to the $-\mathrm{SO}_{3}$ functional groups of DYE molecules (L-PD) and insignificantly dropped to $4.5 \pm 0.8 \mathrm{mV}$ after loaded with PTX. As we hypothesized that the disulfide linkages could be cleaved in response to high concentrations of GSH, XPS analysis before and after GSH treatment under different $\mathrm{pH}$ conditions was performed (Figure $1 \mathrm{~b}$ and Figure S6). Without GSH at physiological pH, PTX loaded L-PD showed a strong disulfide (-S-S-) bond peak at $164 \mathrm{eV}$ as compared to the thiol group $(-\mathrm{S}-\mathrm{H}$; $162 \mathrm{eV}$ ), as displayed in Figure 1b. In contrast, the disulfide bond peak significantly decreased whereas the thiol peak remarkably increased after GSH treatment, confirming the cleavage of -S-S- bonds by GSH $[17,24]$.
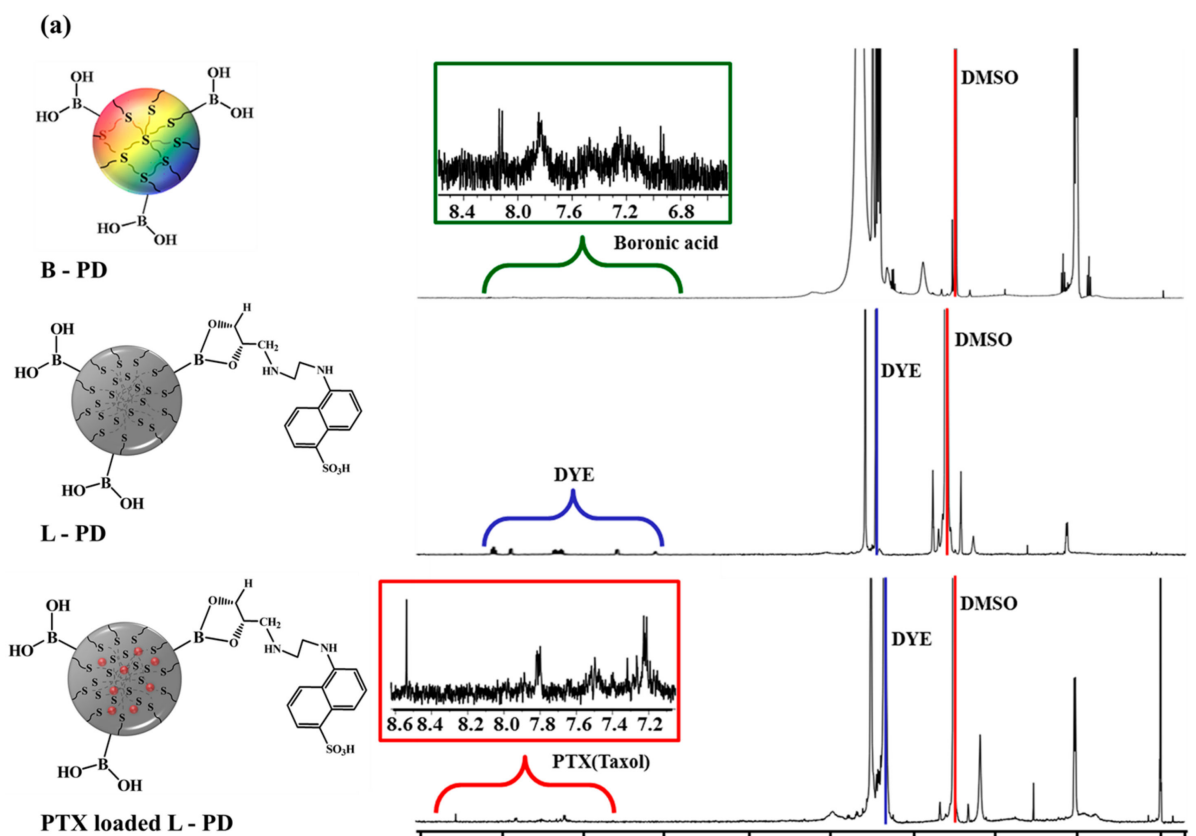

(b)

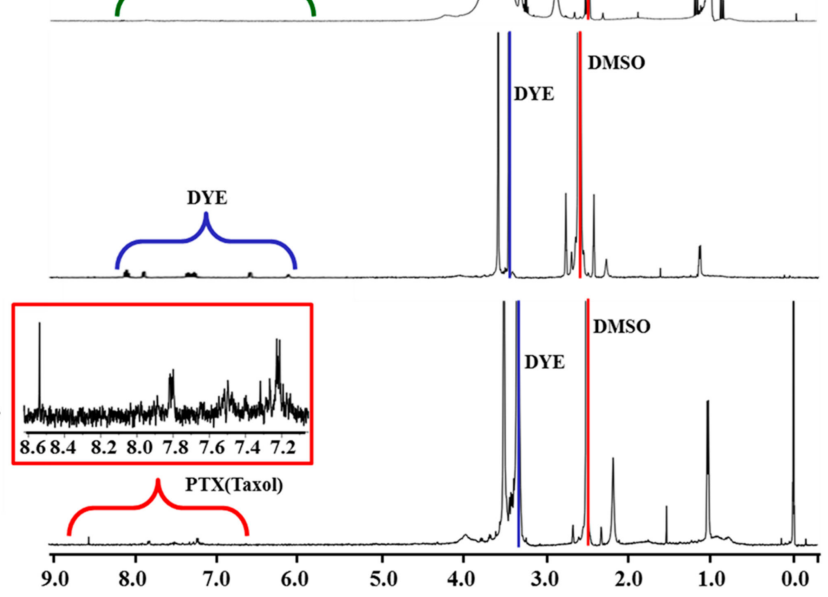

pH 7.4, 0 mM GSH
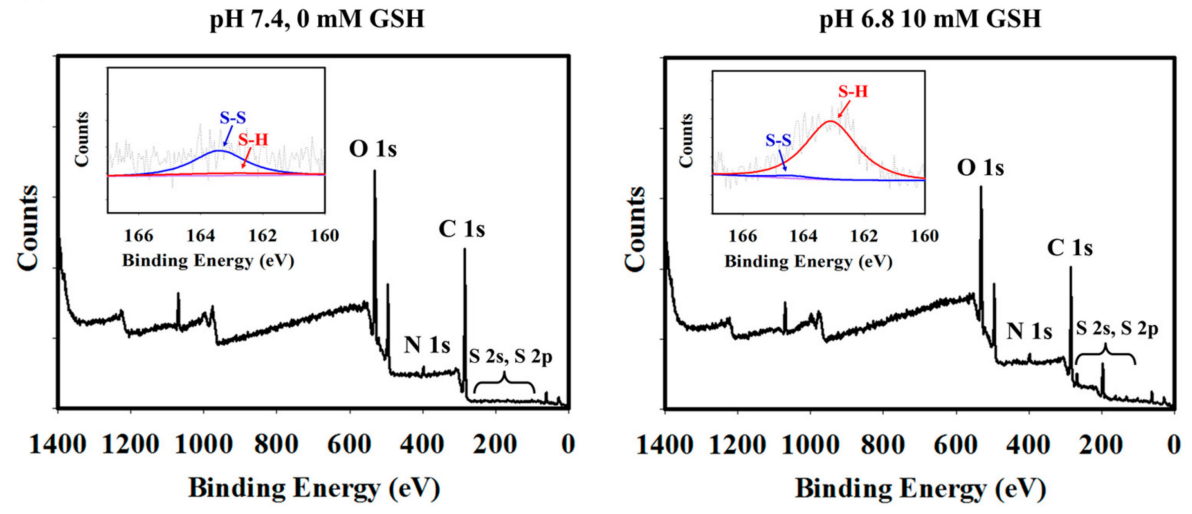

Figure 1. (a) ${ }^{1} \mathrm{H}$ NMR spectra of redox-responsive fluorescence PD (B-PD), L-PD, and PTX loaded L-PD. (b) XPS full survey scan of PTX loaded L-PD at pH 7.4, 0 mM GSH (left) and after treatment at pH 6.8, 10 mM GSH (right). 
Real-time monitoring based on the fluorescence OFF/ON nano-hybrid system has promising potential in simultaneous diagnosis and therapy $[25,26]$; hence, photoluminescence analysis was conducted. As presented in Figure 2a, the fluorescence intensity of the B-PD was high, described as fluorescence "ON", which then greatly decreased when conjugated with DYE (L-PD), described as fluorescence "OFF" (Figure S2b,c). This decrease was due to the formation of boronate ester bonds, causing the Förster resonance energy transfer (FRET) phenomenon $[23,27,28]$. Additionally, the fluorescence remained quenched when the PTX was introduced, indicating no fluorescence recovery when the hydrophobic drug was loaded (Figure S2d). In the UV-vis spectra of the PTX loaded L-PD, we observed broad absorbance peaks in the $300-400 \mathrm{~nm}$ region for $\pi-\pi$ bonding of PD with a PTX absorption peak at $230 \mathrm{~nm}$, which represents loading PTX into the core of the PD (Figure S2a) [29]. Moreover, the average size distribution of nanoparticles in the aqueous state at each step was observed using dynamic light scattering (DLS; Figure S4). The B/S-Pluronic nanoparticles size was $252.06 \mathrm{~nm}$ with a polydispersity index (PDI) value at 0.361 suggesting the monodispersity of the samples. After carbonization process, the size of B-PD in aqueous solution become $169.24 \mathrm{~nm}$ $(\mathrm{PDI}=0.261)$, which elevated to $238.52 \mathrm{~nm}(\mathrm{PDI}=0.310)$ due to the conjugation between the DYE nanoparticles and the polymer dots (boron-ester). Furthermore, the successful loading of PTX was observed after the particle size increased to $245.66 \mathrm{~nm}(\mathrm{PDI}=0.365)$ [30]. To investigate the stability of the hydrophobic drug-loaded matrix in biological fluid before reaching the cancer cells, DLS and UV-vis spectra analyses were performed at different times. Figure $2 b$ displays the hydrodynamic sizes and absorption intensities of the PTX loaded L-PD in different solutions over 4 days. No change in size is observed in media and BSA solutions, indicating the high stability of the nano-hybrid system in physiological conditions. TEM images of PTX loaded L-PD before treatment, shown in Figure 2c, exhibited a dot-like morphology with a diameter of around $220 \mathrm{~nm}$ and a lattice spacing similar to that of graphene $(0.28-0.34 \mathrm{~nm})$ [29]. However, the size decreased to around $45 \mathrm{~nm}$ when treated with $10 \mathrm{mM}$ GSH at $\mathrm{pH}$ 6.8, which is consistent with the DLS results. The size of the PTX loaded L-PD decreased even more to $37.618 \mathrm{~nm}$ in the presence of $10 \mathrm{mM} \mathrm{GSH}$ at acidic $\mathrm{pH}$, contributing to the further cleavage of disulfide bonds in the core and DYE disembarkment from the shell [23]. Moreover, the fluorescence decay of the PTX loaded L-PD was analyzed to understand the quenching phenomena caused by DYE nanoparticles. The fluorescence lifetime of the B-PD decreased when DYE was introduced to the nanoparticles (L-PD). Additionally, fluorescence recovery was observed after treatment with pH 6.8 and $10 \mathrm{mM} \mathrm{GSH}$, further confirming the cleavage of boron-diol conjugation, as shown in Figure 2d [31].

As shown in Figure 3a, for PTX loaded L-PD at physiological pH without GSH, the fluorescent intensity of the PTX loaded L-PD did not show any significant increase due to the non-responsive behavior of the boron-diol conjugation at $\mathrm{pH}$ 7.4, even after GSH treatment, confirming the stability of the fluorescent quenching state of the nano-hybrid system. Next, the $\mathrm{pH}$ of the solution was varied from 6.0 to 7.4 to study the dot sizes and fluorescent intensity changes. The photoluminescence (PL) signal of the PTX loaded L-PD at $\lambda=360 \mathrm{~nm}$ displays specific enhancement in acidic $\mathrm{pH}$ depending on the reaction time [32]. In addition, changes in the PL profile under different $\mathrm{pH}$ conditions evaluated after $10 \mathrm{mM}$ treatment shows that all the fluorescence intensities were higher, not just those subjected to acid treatment (Figure 3b). Furthermore, the combination of both acidic $\mathrm{pH}$ and $10 \mathrm{~mm}$ GSH showed higher fluorescence recovery rather than single treatments. High GSH concentration in cancer cells confirm the possibility of using reduction-oxidation to change the disulfide bonds into thiol bonds, whereas acidic $\mathrm{pH}$ values in tumor cells induce hydrolysis of the L-PD boron-diol covalent bond [33]. The simultaneous GSH and acid treatments supported effective splitting of the PTX loaded L-PD nanoparticles to release PTX, resulting in much smaller particles and distinguish fluorescence response. In similar experimental groups and preparation techniques, the hydrodynamic diameter change was observed using DLS measurements over time, as shown in Figure 3c,d. These figures also confirm that high GSH concentrations and low $\mathrm{pH}$ values resulted in greater cleavage of the disulfide cross-linked sites to generate smaller particles, whereas no significant change was observed at low 
levels of GSH [17]. The same phenomenon was observed in the L-PD when treated with different $\mathrm{pH}$ values and GSH concentrations (Figure S5).

(a)

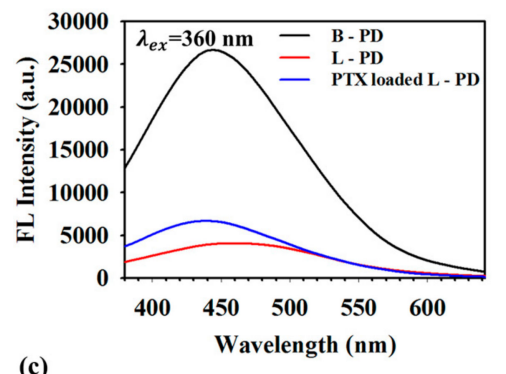

(c)

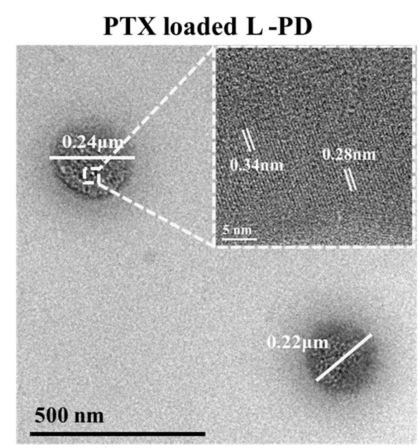

(b)

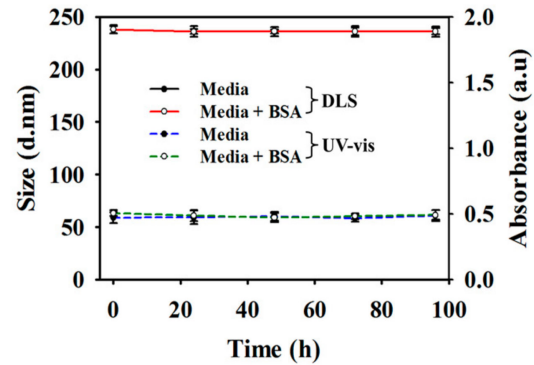

After pH 6.8, $10 \mathrm{mM}$ GSH treatment

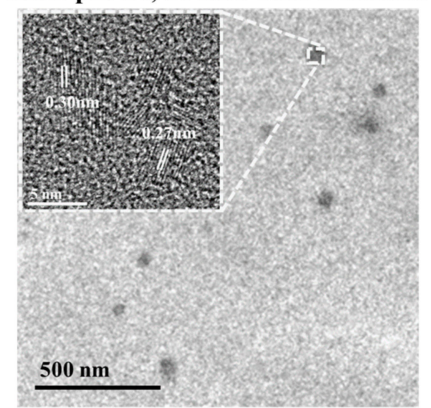

(d)

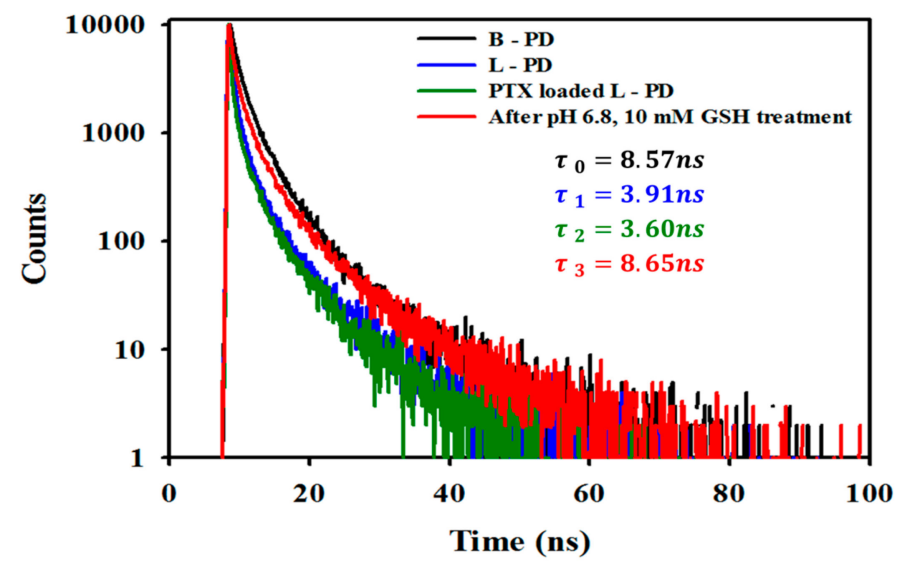

Figure 2. (a) Photoluminescence spectra of B-PD, L-PD, and PTX loaded L-PD (excitation $\lambda=360 \mathrm{~nm}$ ). (b) Time-dependent stability test at $1 \mathrm{mg} / \mathrm{mL}$ of PTX loaded L-PD by dynamic light scattering (DLS) and UV-vis absorbance at $260 \mathrm{~nm}(n=3)$. (c) TEM images of PTX loaded L-PD before and after $\mathrm{pH}$, GSH treatment. (d) Fluorescence decay analysis of B-PD, L-PD, and PTX loaded L-PD before and after $10 \mathrm{mM}$ GSH, pH 6.8 treatment at an excitation wavelength of $360 \mathrm{~nm}$. 
(a)

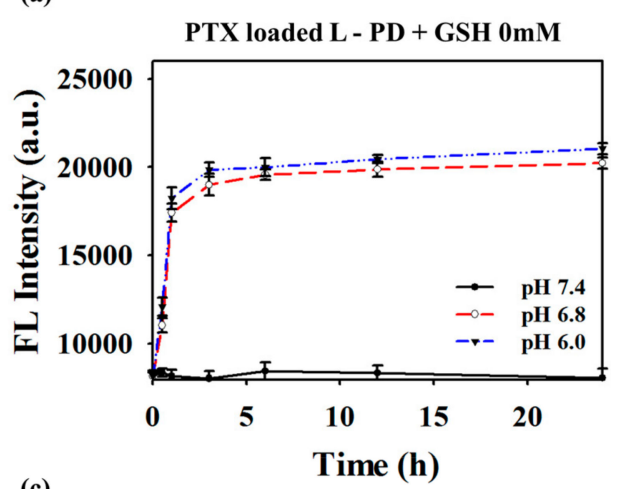

(c)

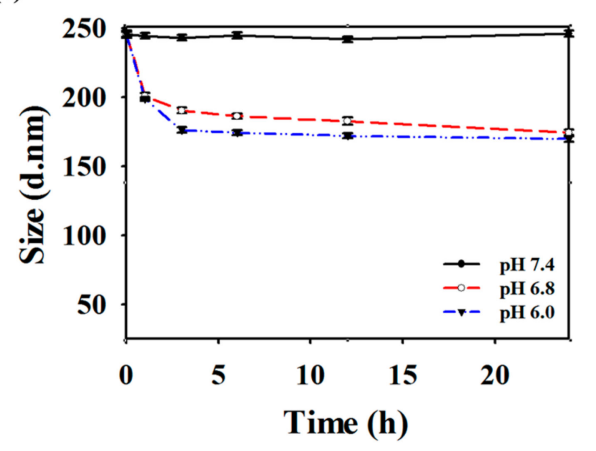

(b)
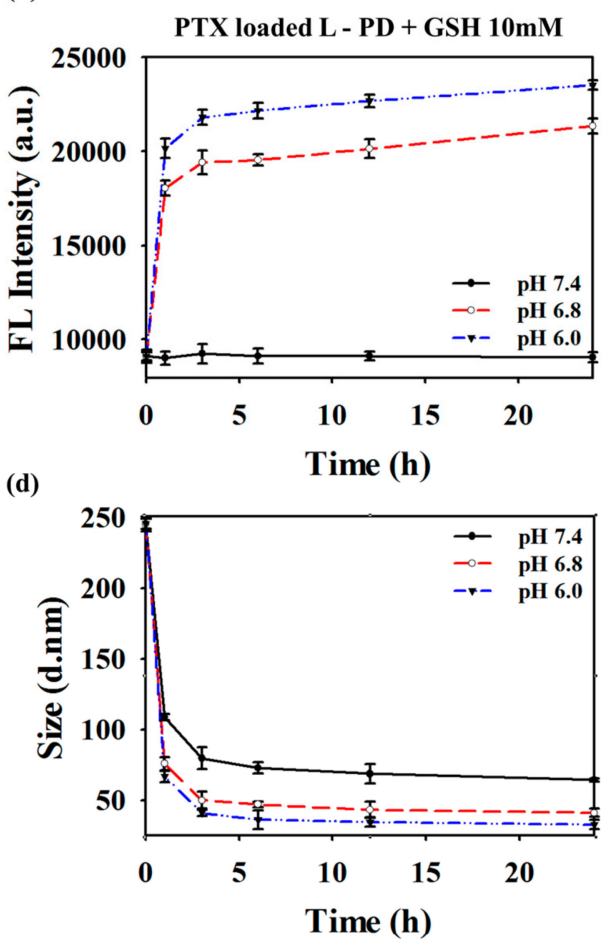

Figure 3. Time-dependent (a,b) luminescence intensity with excitation at $\lambda=360 \mathrm{~nm}$ and (c,d) DLS measurements of PTX loaded L-PD at (a,c) 0 mM GSH and (b,d) $10 \mathrm{mM} \mathrm{GSH}$ treatments in different $\mathrm{pH}$ solutions $(6.0,6.8$, and $7.4 ; n=3)$.

\subsection{Stimuli-Responsive Drug Release and Anticancer Efficacy Evaluation of PTX Loaded L-PD}

The release of PTX in response to acidic and GSH levels in cancer cells were evaluated by UV-vis spectroscopy over time. The loading content (\%LC) and encapsulation efficiency (\%EE) of PTX were $7.708 \%$ and $83.52 \%$, respectively. The successful loading of PTX in the nano-hybrid matrices was dependent on $\pi-\pi$ stacking and hydrophobic interactions between PTX and the L-PD. However, the attachment of DYE to the B-PD was determined by the boron-diol conjugation of both types of nanoparticles. The PTX and DYE release profile were conducted at absorbance values $230 \mathrm{~nm}$ and 335 $\mathrm{nm}$, respectively, as depicted in Figure 4a,b, respectively. As shown in Figure 4a, the amount of PTX released was less than $5 \%$ in the absence of GSH regardless whether $\mathrm{pH}$ was at the physiological or the acidic level, suggesting that there was no breakage of L-PD crosslinking and stable hydrophobic interactions. However, burst release was observed after treatment with GSH, which was related to the cleavage of disulfide bonds in the L-PD core. Specifically, 31.8\% and 32.1\% of PTX amount was released from the PTX loaded L-PD cargo during the first $60 \mathrm{~min}$ and $100 \%$ after $24 \mathrm{~h}$ in the presence of GSH. Disintegration of boron-diol covalent bond of B-PD and DYE was observed in the form of the release profile of DYE (Figure $4 \mathrm{~b}$ ). At pH 7.4 and GSH concentrations of either $0 \mathrm{mM}$ or $10 \mathrm{mM}$, less than $5 \%$ of DYE was released, even after $24 \mathrm{~h}$, suggesting no boron-diol cleavage on the shells of the L-PD. Additionally, we investigated DYE release under acidic $\mathrm{pH}$ conditions and GSH concentrations of $0 \mathrm{mM}$ and $10 \mathrm{mM}$. The results showed a high percentage of DYE, corresponding to the $\mathrm{pH}$ effect on the nano-hybrid matrix that induced hydrolysis of the boron-diol covalent bond between DYE and the drug carrier. It should be noted that $23.7 \%(0 \mathrm{mM} \mathrm{GSH})$ and $25.3 \%$ (10 mM GSH) of DYE released from the PTX loaded L-PD matrices in the first $60 \mathrm{~min}$ after $\mathrm{pH}$ treatment. To understand the efficient delivery, therapeutic performance, and biocompatibility, MTT assay was performed using Madin-Darby canine kidney (MDCK) and breast cancer cell lines (MDA-MB-231) cells. The L-PD nanoparticles demonstrated excellent biocompatibility across a wide range of concentrations from 0.01 to $1.5 \mathrm{mg} / \mathrm{mL}$, as displayed in Figure 4c. Moreover, the viability of the cells remained high for 
the MDCK cells, even with the presence of PTX, indicating no release or leakage during incubation. However, the number of dead cells remarkably increased for the MDA-MB-231 cells, which had a cell survival of only $37 \%$, which further supported the anticancer effect of the released PTX after cleaving of boron-diol covalent bonds by $\mathrm{pH}$ and disulfide bonds by GSH. These phenomena suggest the selectivity of PTX loaded L-PD to the $\mathrm{pH}$ environment and GSH concentrations that effectively promoted the therapeutic performance of the nano-hybrid system.
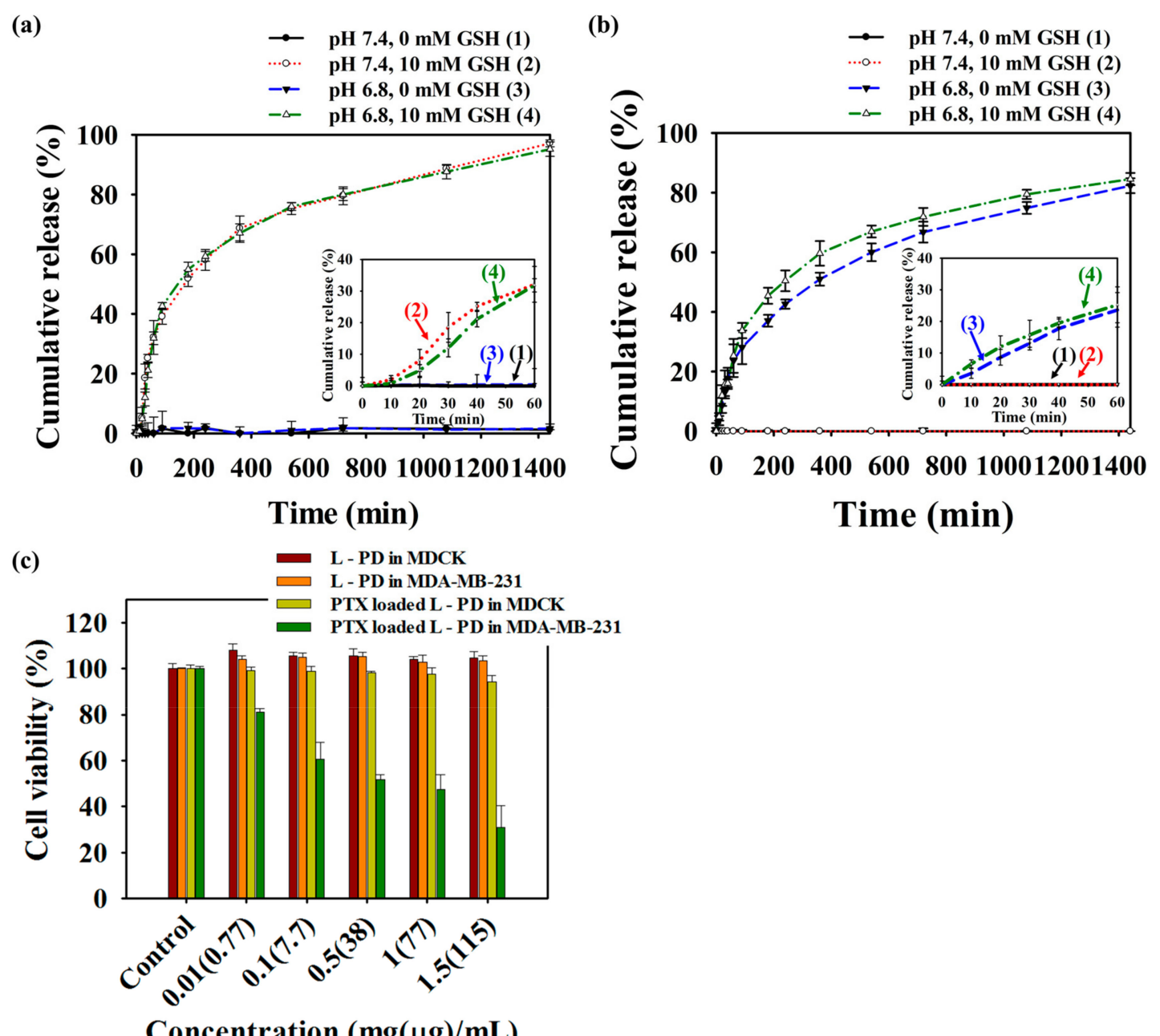

\section{Concentration $(\mathrm{mg}(\mu \mathrm{g}) / \mathrm{mL})$}

Figure 4. In vitro release profile of (a) PTX and (b) fluorescent dye (DYE) from PTX loaded L-PD matrices under different concentrations of GSH at physiological ( $\mathrm{pH}$ 7.4) and tumor ( $\mathrm{pH}$ 6.8) conditions; inset: first 60 min of release profile. (c) Cell viability of Madin-Darby canine kidney (MDCK) and breast cancer cell lines (MDA-MB-231) after treatment with different concentrations of L-PD and PTX loaded L-PD $(n=5)$. Parentheses $(\mu \mathrm{g})$ : PTX concentration in PTX loaded L-PD samples.

\subsection{Fluorescence OFF/ON Behavior Based on Confocal Imaging}

Further investigation to confirm the fluorescence OFF/ON behavior to distinguish normal and cancer conditions was performed using confocal images. Figure 5a displays the images of MDCK cells after incubation with PTX loaded L-PD for different times. No fluorescence signal was revealed from 0-5 h treatment of the MDCK cells, which indicates the stability of PTX loaded L-PD at physiological $\mathrm{pH}$ and low concentrations of GSH. In the MDA-MB-231 cells, fluorescence recovery was observed after only $0.5 \mathrm{~h}$, and it remained stable up to $3 \mathrm{~h}$ (Figure $5 \mathrm{~b}$ ) due to the hydrolysis of the boron-diol covalent bonds at acidic $\mathrm{pH}$, which increased the fluorescence emission. Moreover, the fluorescence signal diminished after $5 \mathrm{~h}$, corresponding to the endosomal escape of the nanoparticles from the liposomal 
vesicles. To understand the fluorescence $\mathrm{OFF} / \mathrm{ON}$ behavior of the nanoparticles by using the color changes of stimuli-responsive PD as a function of the cellular environment of the normal and tumor cells, flow cytometry analysis was conducted. In Figure 5c, MDCK shows an insignificant increase of intensity when treated with PTX loaded L-PD. However, MDA-MB-231 treated with PTX loaded L-PD increased to $96.445 \%$, demonstrating the increase of PD fluorescence intensity in a tumor environment as an effect of the cleavage of DYE-PD boron-diol bonds by the $\mathrm{pH}$ condition and disulfide bonds by GSH.

(a)

\section{MDCK}

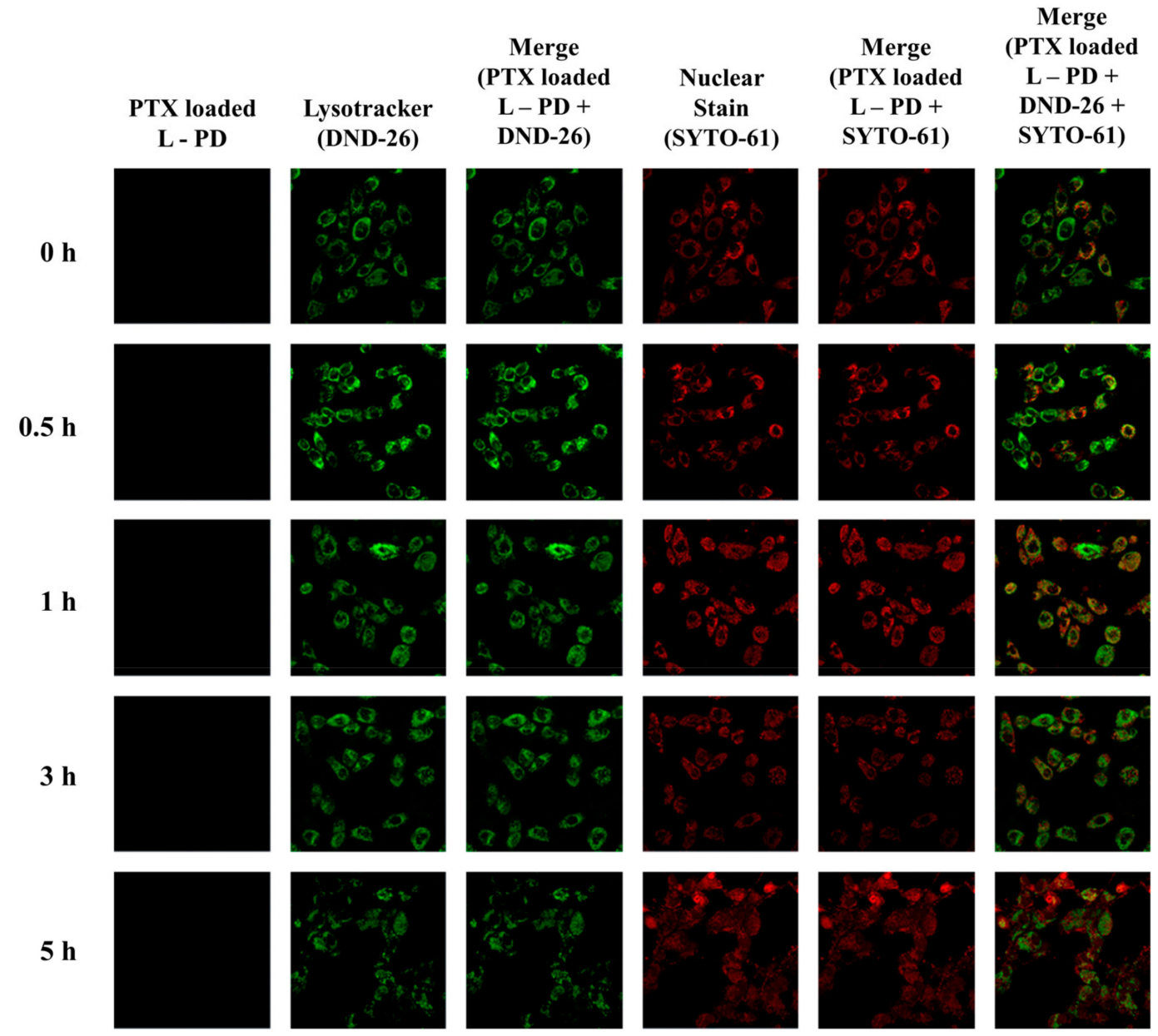

Figure 5. Cont. 
(b)

MDA-MB-231

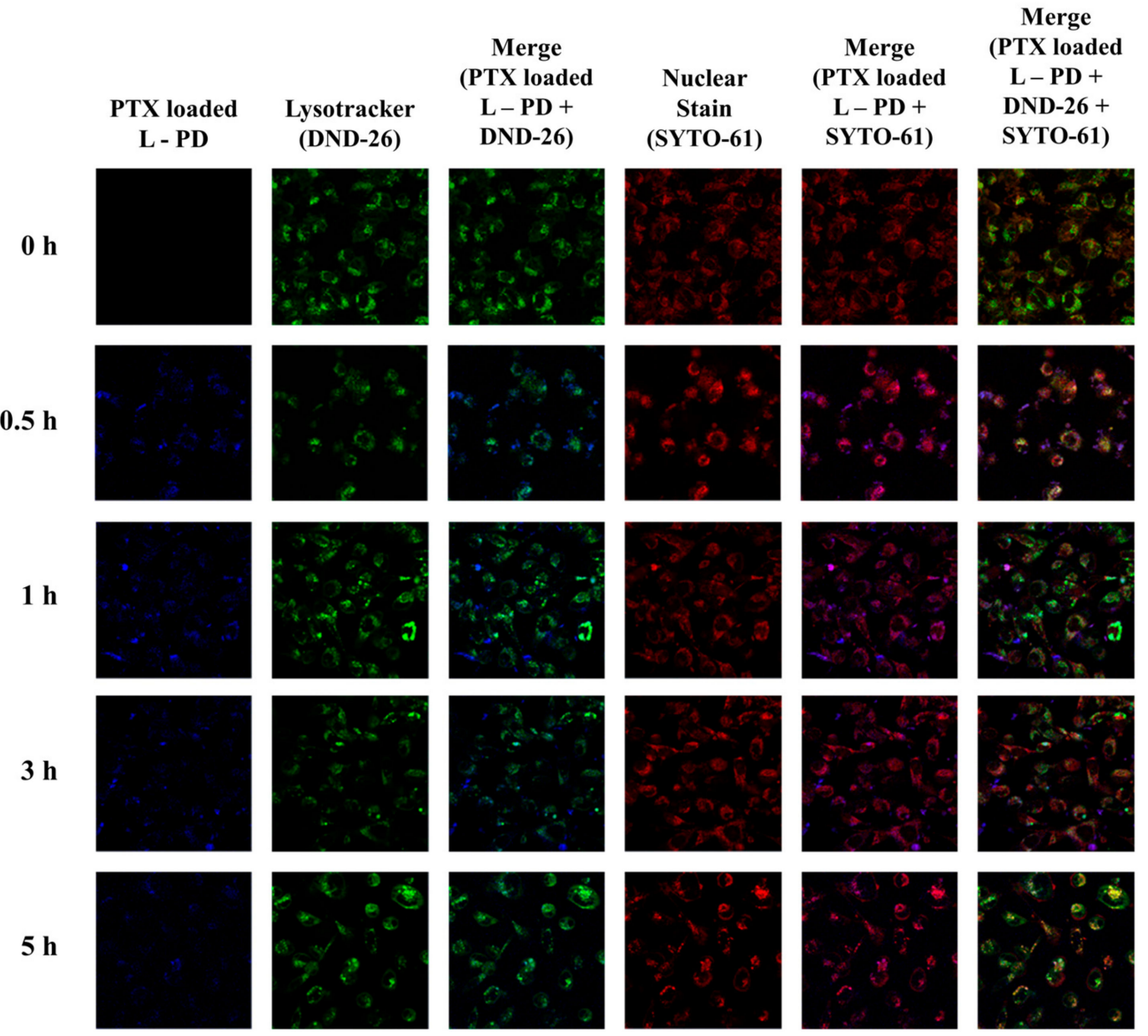

(c)

MDCK

MDA-MB-231
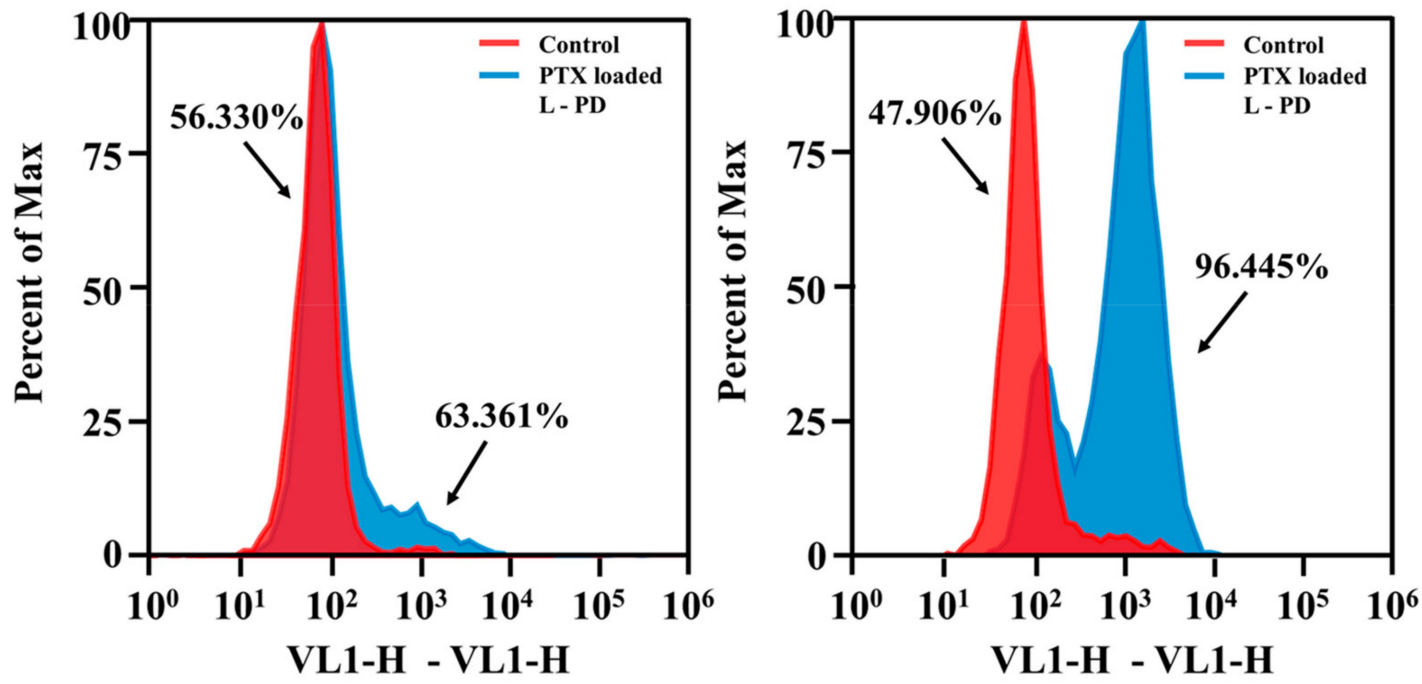

Figure 5. Confocal images of (a) MDCK and (b) MDA-MB-231 treated with PTX loaded L-PD at different incubation times $(0 \mathrm{~h}, 0.5 \mathrm{~h}, 1 \mathrm{~h}, 3 \mathrm{~h}$, and $5 \mathrm{~h}$ ) stained with a Lysotracker (green) and SYTO 61 (red). (c) Flow cytometric (FACS) analysis of in vitro quantitative fluorescence behavior of MDCK and MDA-MB-231 after treatment without (control) and with PTX loaded L-PD. (Scale Bar: $40 \mu \mathrm{m}$ ). 


\subsection{Apoptosis/Necrosis Analysis and Live/Dead Assay}

Further study of PTX loaded L-PD cytotoxicity was proven to be necessary, and therefore flow cytometry was conducted to investigate cellular apoptosis/necrosis using annexin $\mathrm{V}$ and propidium iodide (PI). The MDCK cells demonstrated excellent survivability when treated with PTX loaded L-PD as no cells reached late apoptosis and necrosis (Figure 6a). However, a higher percentage of apoptosis cells were counted when the MDA-MB-231 cells were treated with PTX loaded L-PD, corresponding to the release of the drug from the nano-hybrid matrices and the therapeutic effect of PTX. To monitor the cytotoxicity of the PTX loaded L-PD, an in vitro live and dead assay was performed using calcein $\mathrm{AM}$ and PI staining. After $3 \mathrm{~h}$ incubation with the nanoparticles, confocal images of the MDCK cells (Figure 6b) revealed that most of the cells survived (green), which was in contrast to the MDA-MB-231 cells, which were killed (red), indicating the high cytotoxicity of the PTX loaded L-PD.

(a)
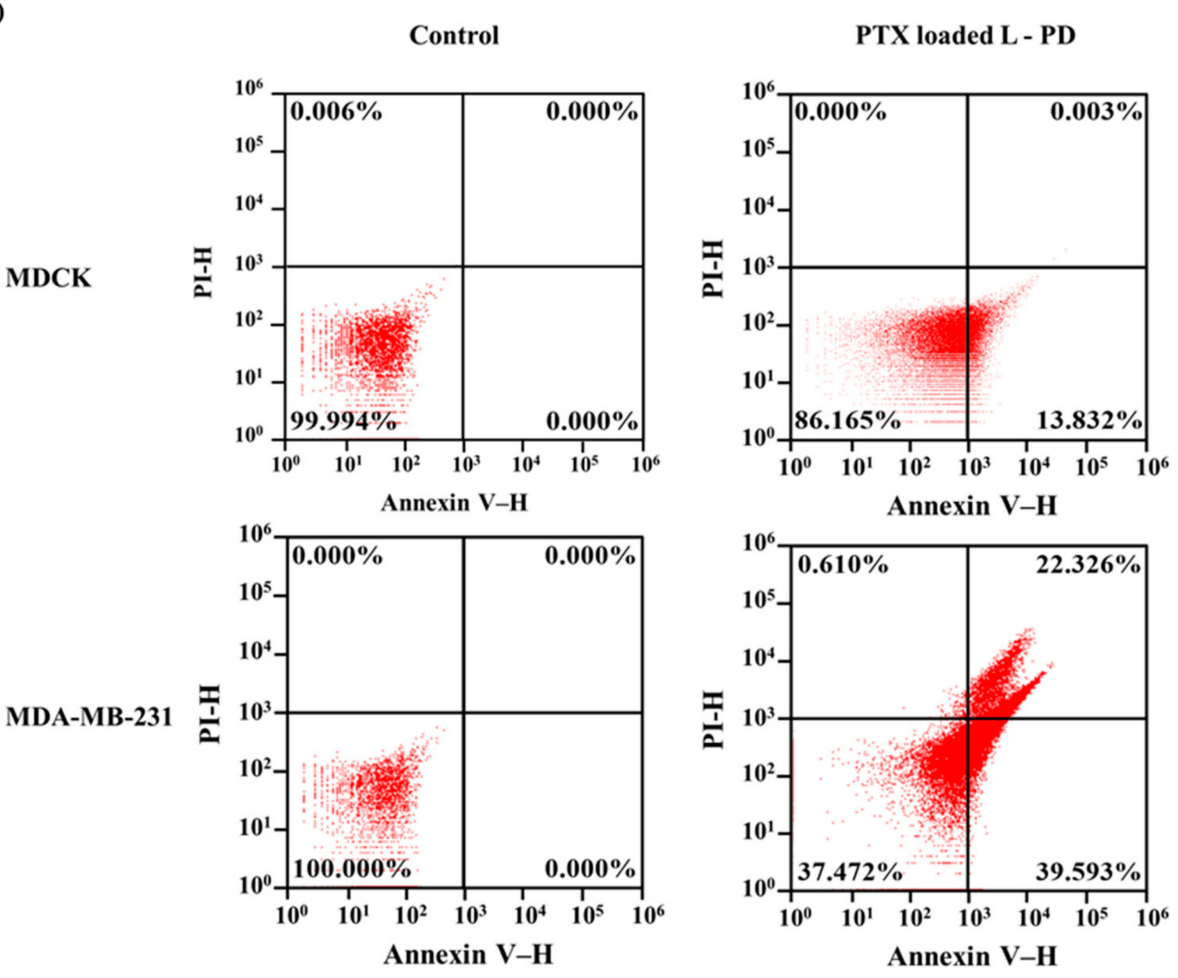

(b)

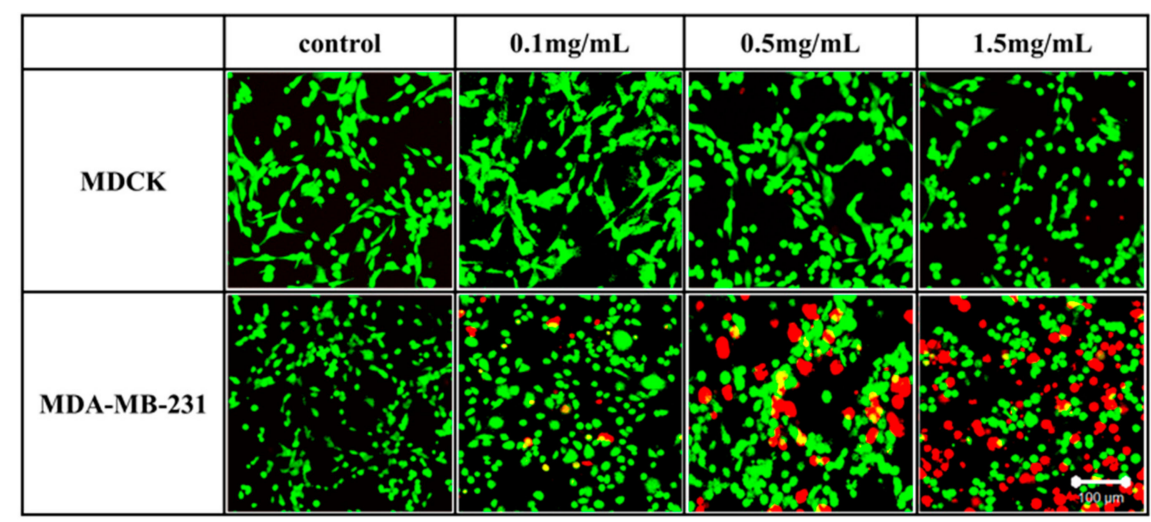

Figure 6. (a) Apoptosis assay of MDCK and MDA-MB-231 analyzed with flow cytometry. (b) Live and dead cell imaging spectroscopy of MDCK and MDA-MB after treatment with PTX loaded L-PD (Scale Bar: $100 \mu \mathrm{m})$. 


\section{Materials and Methods}

\subsection{Materials and Characterization}

Pluronic F-127, 2-(dimethylamino)ethyl methacrylate (DMA), 2-hydroxyethyl methacrylate (HEMA), 4-chlorophenylboronic acid, t-butylperoxybenzoate, sulfuric acid $\left(\mathrm{H}_{2} \mathrm{SO}_{4}\right)$, cysteamine, ethanol (EtOH), trizma base, toluene, hexane, diethyl ether, paclitaxel (PTX), and glutathione (GSH) were obtained from Sigma-Aldrich, Yongin-si, Gyeonggi-do, Korea. Fetal bovine serum (FBS), penicillin-streptomycin, trypsin-ethylenediaminetetraacetic acid (trypsin-EDTA, 0.03\% $w / v$ ), and Roswell Park Memorial Institute (RPMI)-1640 medium were obtained from Gibco BRL, NY, USA. Phosphate-buffered saline (PBS) pH 7.4 was purchased from Bioneer Corp, Daejeon, Korea. Cell staining dyes (Annexin V, propidium iodide (PI), LysoTracker Green DND-26, and MitoTracker Red CMXRos) were procured from Life Technologies, Oregon, USA. The fluorescent probe (DYE) nanoparticles synthesis process was provided in a previous report [34].

Structural analyses were conducted using ${ }^{1} \mathrm{H}$ nuclear magnetic resonance (NMR) using deuterium oxide (Bruker AVANCE $400 \mathrm{MHz}$ spectrometer), UV-vis spectrophotometry (Optizen 2020UV spectrometer, Mecasys Co.), Fourier transform infrared (FTIR) spectra (Thermo Scientific, Madison, WI, USA), and X-ray photoelectron spectroscopy (XPS, Omicrometer ESCALAB apparatus, Taunusstein). The fluorescence behavior was observed using a model L550B luminescence spectrometer (PerkinElmer) and the nanoparticle size was evaluated using a Zetasizer Nano device (Malvern). Cell relating analyses were performed using 3-(4,5-dimethylthiazol-2-Yl)-2,5-diphenyltetrazolium bromide (MTT) methods, flow cytometry (Attune NxT Acoustic Focusing Cytometer, Life Technologies), and confocal microscopy images (LSM510 confocal microscope, Carl Zeiss). Transmission electron microscopy (TEM) imaging was obtained using a JEM-2100F microscope (JEOL). Surface charges were measured by a zeta-potential and particle size analyzer (ELSZ; Otsuka Electronics, Japan).

\subsection{Synthesis of Carbonized Disulfide-Crosslinked Pluronic-Grafted Poly(DMA), Poly(HEMA) Quaternized Boronic Acid-Cysteamine (B-PD)}

The S-Pluronic nanoparticles were synthesized as previously reported [23]. B/S-Pluronic was obtained by dissolving S-Pluronic in ethanol, followed by the addition of 4-chlorophenylboronic acid and stirred for $24 \mathrm{~h}$ at $70{ }^{\circ} \mathrm{C}$. The product was then poured into diethyl ether to obtain a purified B/S-Pluronic powder.

To synthesize carbonized disulfide crosslinked B/S-Pluronic, $2 \mathrm{~g}$ of the obtained powder (B/S-Pluronic) was dissolved in $1 \%$ DMSO in $10 \mathrm{~mL}$ of deionized water (DDW) and stirred at $25{ }^{\circ} \mathrm{C}$ in air. After $48 \mathrm{~h}, 10 \mathrm{~mL}$ of concentrated sulfuric acid was added and reacted for $1 \mathrm{~min}$, followed by the addition of $185 \mathrm{~mL}$ of DDW. The product was then dialyzed (MWCO: $3500 \mathrm{Da}$ ) for 1 day, freeze-dried, and was labeled as B-PD. (82\% Yield).

\subsection{Synthesis of the Diol-Conjugated Fluorescent Probe-B-PD (L-PD)}

The carbonized disulfide-crosslinked B/S-Pluronic (100 mg) and DYE $(0.001 \mathrm{mg} / \mathrm{mL})$ were dissolved in $10 \mathrm{~mL}$ of Tris-buffered saline (TBS) at $\mathrm{pH}$ 12.0. The mixture was stirred for $24 \mathrm{~h}$ at room temperature. The solution was dialyzed (MWCO $1 \mathrm{kDa}$ ) against water overnight, freeze-dried, and labeled as L-PD (67\% Yield).

\subsection{Drug Loading into L-PD (PTX Loaded L-PD) and Release Profiles}

First, $100 \mathrm{mg}$ of the L-PD in $20 \mathrm{~mL}$ of PBS (pH 7.4) and $5 \mathrm{mg}$ of PTX in ethanol were stirred together overnight at $24-25^{\circ} \mathrm{C}$. The sample was then purified by dialysis (MWCO $1 \mathrm{kDa}$ ) for $24 \mathrm{~h}$ and freeze-dried to achieve PTX loaded L-PD (76\% yield). The PTX loading content (\%LC) and 
PTX encapsulation efficiency (\%EE) were measured with a UV-vis spectrophotometer at $225 \mathrm{~nm}$ and calculated using following equations [24]:

$$
\begin{gathered}
\% \mathrm{LC}=\frac{\text { weight of drug into the carrier }}{\text { weight of nanoparticles }} \times 100 . \\
\% \mathrm{EE}=\frac{\text { weight of PTX loaded in nanoparticles }}{\text { weight of PTX in Feed }} \times 100 .
\end{gathered}
$$

The drug release profile was performed at different concentrations of GSH $(0,3,6$, and $10 \mathrm{mM})$ inside the chamber while soaked in approximately $30 \mathrm{~mL}$ of release solutions at $\mathrm{pH}$ values of 6.8 and 7.4. The sample was positioned inside a shaking incubator at $37^{\circ} \mathrm{C}$ and evaluated with UV-vis spectrophotometry to quantify the release of PTX.

\subsection{Cytotoxicity Assay}

To evaluate the cytotoxicity of the PTX loaded L-PD, MDCK and MDA-MB-231 cells at densities of $1 \times 10^{5}$ cells/mL were cultured in a $37^{\circ} \mathrm{C}$ incubator (humidified $5 \% \mathrm{CO}_{2}$ atmosphere) for $24 \mathrm{~h}$. A stock solution containing the PTX loaded L-PD in RPMI-1640 medium $(1.5 \mathrm{mg} / \mathrm{mL})$ was prepared and diluted to $0.01 \mathrm{mg} / \mathrm{mL}$ serially. The cell media was replaced with stock solution and incubated overnight. The MTT solution was added after the removal of the stock solution. The cell viability was evaluated by using a microplate reader with an absorbance wavelength of $570 \mathrm{~nm}$ [35].

\subsection{Flow Cytometry}

The flow cytometry was conducted by culturing MDCK and MDA-MB-231 cells in six-well plates at densities of $1 \times 10^{6}$ cells $/ \mathrm{mL}$ for $24 \mathrm{~h}$ at $37^{\circ} \mathrm{C}\left(5 \% \mathrm{CO}_{2}\right)$. The medium was then changed with a stock solution (dissolved PTX loaded L-PD in media) followed by incubation at the designated time. The samples were then collected and dissolved with 1\% FBS in PBS (pH 7.4) and evaluated using filter at excitation wavelength of $405 \mathrm{~nm}$ and an emission wavelength of $440 / 50 \mathrm{~nm}$.

For apoptosis assays, the cells were directly evaluated after stained with annexin V and PI using an excitation wavelength of $488 \mathrm{~nm}$ and emission wavelengths of 530/30 nm and 574/26 nm, respectively.

\subsection{Confocal Imaging}

The time-dependent internalization of the PTX loaded L-PD was investigated using confocal laser-scanning microscope (magnification 20x). First, the cells were cultured then treated with sample $(1 \mathrm{mg} / \mathrm{mL})$ in medium (different incubation time). The medium was then removed, washed with PBS (pH 7.4), stained with LysoTracker Green (acidic compartment) for 30 min and SYTO 61 (nucleic acid) for $15 \mathrm{~min}$, and observed using a confocal microscope.

For live/dead cell analysis, cultured MDCK and MDA-MB-231 cells were incubated with PTX loaded L-PD $(0.2 \mathrm{mg} / \mathrm{mL})$ for $3 \mathrm{~h}$. Then, the prepared cells were stained with calcein AM and PI and placed under confocal laser-scanning microscope (magnification, 10x) to evaluate the stained cells (live or dead).

\section{Conclusions}

In conclusion, a dual-sensitive fluorescent polymer dots (PD) as a paclitaxel (PTX) drug carrier was successfully developed based on a disulfide bond as core-crosslinked and boron-ester as shell-cleavable parts. The PTX loaded L-PD nano-hybrid system core part utilized disulfide bond as a redox-responsive site and for stabilizing the inner structure, which avoid the leaks of PTX drugs during treatment. Meanwhile, the attachment of DYE on the shell part of PD was beneficial for a $\mathrm{pH}$-sensitive bioimaging probe due to the fluorescence quenching at the alkali condition, which recovered at acidic $\mathrm{pH}$ owing to boron-ester hydrolysis. The PTX loaded L-PD demonstrated low fluorescence intensity at physiological $\mathrm{pH}$, which recovered after the $\mathrm{pH}$ become acidic. Additionally, the release of PTX, which was 
expected to show distinguish result during different GSH concentrations, was proven to be the same as hypothesized with burst released detected at high concentration of GSH. Moreover, time dependent MDCK treated PTX loaded L-PD confocal images displayed no fluorescent signal while MDA-MB-231 started to showed a fluorescence signal at $30 \mathrm{~min}$ treatment. Hence, this nanosystem represents an improved system for differentiating between normal and tumor sites depending on the surrounding $\mathrm{pH}$ and GSH concentrations, which could enable controlled release of drugs with bioimaging abilities, showing its high potential for further applications in cancer diagnosis and treatment.

Supplementary Materials: Supplementary materials can be found at http://www.mdpi.com/1422-0067/20/21/5368/s1. Scheme S1: Synthesis of B/S Pluronic.; FigureS1: Fourier-transform Infrared (FT-IR) spectra of B-PD, L-PD, and PTX loaded L-PD.; Figure S2: (a) UV-vis spectra of B-PD, L-PD, and PTX loaded L-PD (concentration $1 \mathrm{mg} / \mathrm{mL}$ ). Photoluminescence spectra of (b) B-PD, (c) L-PD, and (d) PTX loaded L-PD.; Figure S3: Zeta potentials of B/S-Pluronic, B-PD, L-PD, and PTX loaded L-PD in PBS pH $7.4(n=3)$.; Figure S4: Average size distribution of of B/S-Pluronic, B-PD, L-PD, and PTX loaded L-PD in PBS solution pH 7.4 (Concentration: $0.5 \mathrm{mg} / \mathrm{mL}$ ).; Figure S5: $(\mathrm{a}, \mathrm{b})$ Luminescence intensity with excitation at $\lambda=$ $360 \mathrm{~nm}$ and $(\mathrm{c}, \mathrm{d})$ DLS measurements of L-PD at different GSH concentrations ( 0 and $10 \mathrm{~mm} \mathrm{GSH})$ and $\mathrm{pH}$ values (6.0, 6.8, and 7.4) over time $(n=3)$ ); Figure S6: XPS narrow scan (C 1s, N 1s, and O 1s) of PTX loaded L-PD at pH 7.4 and 0 $\mathrm{mM}$ GSH (a) after treatment at pH 6.8 and $10 \mathrm{mM}$ GSH (b).

Author Contributions: S.G.K. performed experiment. S.G.K., B.R., P.T.M.P., and H.J.W. performed characterization and data acquisition. B.R., P.T.M.P., and S.Y.P. writing and editing. G.L. assisted in statistical analysis and simulation of carbon dots. S.H.B. assisted in cells work. S.Y.P. supervision, experimental design and data acquisition.

Funding: This work was supported by Korea Institute for Advancement of Technology (KIAT) grant funded by the Korea Government (MOTIE) (No. P00008500) and the Basic Science Research Program through the National Research Foundation of Korea (NRF) funded by the Ministry of Education (NRF-2017R1A2B2002365 and 2018R1A6A1A03023788).

Conflicts of Interest: The authors declare no conflict of interest.

\section{Abbreviations}

$\begin{array}{ll}\text { B-PD } & \text { Disulfide-crosslinked Pluronic-grafted poly(DMA), poly(HEMA) quaternized boronic acid-cysteamine } \\ \text { B/S-Pluronic } & \text { Pluronic-grafted poly(DMA), poly(HEMA) quaternized boronic acid-cysteamine } \\ \text { BSA } & \text { Bovine serum albumin } \\ \text { DDS } & \text { Drug delivery system } \\ \text { DDW } & \text { Double distilled water } \\ \text { DMA } & \text { 2-(dimethylamino)ethyl methacrylate } \\ \text { FBS } & \text { Fetal bovine serum } \\ \text { GSH } & \text { Glutathione } \\ \text { HEMA } & \text { 2-hydroxyethyl methacrylate } \\ \text { L-PD } & \text { Diol-conjugated fluorescent probe- B-PD } \\ \text { MC } & \text { Methylene chloride } \\ \text { MDCK } & \text { Madin-Darby Canine Kidney } \\ \text { MTT } & \text { 3-(4,5-dimethylthiazol-2-yl)-2,5-diphenyltetrazolium bromide } \\ \text { NPC } & \text { Nitrophenyl chloroformate } \\ \text { PD } & \text { Polymer dots } \\ \text { PI } & \text { Propidium iodide } \\ \text { PTX } & \text { Paclitaxel } \\ \text { TEA } & \text { Triethylamine }\end{array}$

\section{References}

1. Liu, D.; Yang, F.; Xiong, F.; Gu, N. The Smart Drug Delivery System and Its Clinical Potential. Theranostics 2016, 6, 1306-1323. [CrossRef] [PubMed]

2. Masood, F. Polymeric nanoparticles for targeted drug delivery system for cancer therapy. Mater. Sci. Eng. C. 2016, 60, 569-578. [CrossRef] [PubMed]

3. Estrella, V.; Chen, T.; Lloyd, M.; Wojtkowiak, J.; Cornnell, H.H.; Ibrahim-Hashim, A.; Bailey, K.; Balagurunathan, Y.; Rothberg, J.M.; Sloane, B.F.; et al. Acidity Generated by the Tumor Microenvironment Drives Local Invasion. Cancer Res. 2013, 73, 1524-1535. [CrossRef] 
4. Lv, H.; Zhen, C.; Liu, J.; Yang, P.; Hu, L.; Shang, P. Unraveling the Potential Role of Glutathione in Multiple Forms of Cell Death in Cancer Therapy. Oxid. Med. Cell. Longev. 2019, 2019, 1-16. [CrossRef] [PubMed]

5. Bansal, A.; Simon, M.C. Glutathione metabolism in cancer progression and treatment resistance. J. Cell Biol. 2018, 217, 2291-2298. [CrossRef]

6. Guo, X.; Cheng, Y.; Zhao, X.; Luo, Y.; Chen, J.; Yuan, W.-E. Advances in redox-responsive drug delivery systems of tumor microenvironment. J. Nanobiotechnology 2018, 16, 74. [CrossRef]

7. Wang, Z.; Deng, X.; Ding, J.; Zhou, W.; Zheng, X.; Tang, G. Mechanisms of drug release in pH-sensitive micelles for tumour targeted drug delivery system: A review. Int. J. Pharm. 2018, 535, 253-260. [CrossRef]

8. Li, M.; Tang, Z.; Sun, H.; Ding, J.; Song, W.; Chen, X. pH and reduction dual-responsive nanogel cross-linked by quaternization reaction for enhanced cellular internalization and intracellular drug delivery. Polym. Chem. 2013, 4, 1199-1207. [CrossRef]

9. Miao, K.; Liu, H.; Zhao, Y. Thermo, $\mathrm{pH}$ and reduction responsive coaggregates comprising AB $2 \mathrm{C} 2$ star terpolymers for multi-triggered release of doxorubicin. Polym. Chem. 2014, 5, 3335-3345. [CrossRef]

10. Su, Z.; Xu, Y.; Wang, Y.; Shi, W.; Han, S.; Shuai, X. A pH and reduction dual-sensitive polymeric nanomicelle for tumor microenvironment triggered cellular uptake and controlled intracellular drug release. Biomater. Sci. 2019, 7, 3821-3831. [CrossRef] [PubMed]

11. Wang, S.; Wang, H.; Liu, Z.; Wang, L.; Wang, X.; Su, L.; Chang, J. Smart pH- and reduction-dual-responsive folate-PEG-coated polymeric lipid vesicles for tumor-triggered targeted drug delivery. Nanoscale 2014, 6, 7635-7642. [CrossRef] [PubMed]

12. Parveen, S.; Misra, R.; Sahoo, S.K. Nanoparticles: a boon to drug delivery, therapeutics, diagnostics and imaging. Nanomedicine: NBM. 2012, 8, 147-166. [CrossRef] [PubMed]

13. Senapati, S.; Mahanta, A.K.; Kumar, S.; Maiti, P. Controlled drug delivery vehicles for cancer treatment and their performance. Signal Transduct. Target. Ther. 2018, 3, 7. [CrossRef] [PubMed]

14. Cui, P.-F.; Zhuang, W.-R.; Hu, X.; Xing, L.; Yu, R.-Y.; Qiao, J.-B.; He, Y.-J.; Li, F.; Ling, D.; Jiang, H.-L. A new strategy for hydrophobic drug delivery using a hydrophilic polymer equipped with stacking units. Chem. Commun. 2018, 54, 8218-8221. [CrossRef] [PubMed]

15. Shi, Y.; Lammers, T.; Storm, G.; Hennink, W.E. Physico-Chemical Strategies to Enhance Stability and Drug Retention of Polymeric Micelles for Tumor-Targeted Drug Delivery. Macromol. Biosci. 2017, 17, 1600160. [CrossRef] [PubMed]

16. Li, S.; Hu, K.; Cao, W.; Sun, Y.; Sheng, W.; Li, F.; Wu, Y.; Liang, X.-J. pH-responsive biocompatible fluorescent polymer nanoparticles based on phenylboronic acid for intracellular imaging and drug delivery. Nanoscale 2014, 6, 13701-13709. [CrossRef] [PubMed]

17. Mazrad, Z.A.I.; Phuong, P.T.M.; Choi, C.A.; In, I.; Lee, K.D.; Park, S.Y. pH/Redox-Triggered Photothermal Treatment for Cancer Therapy Based on a Dual-Responsive Cationic Polymer Dot. ChemMedChem 2018, 13, 2437-2447. [CrossRef]

18. Ryplida, B.; Lee, K.D.; In, I.; Park, S.Y. Light-Induced Swelling-Responsive Conductive, Adhesive, and Stretchable Wireless Film Hydrogel as Electronic Artificial Skin. Adv. Funct. Mater. 2019, 1903209. [CrossRef]

19. Du, J.; Choi, B.; Liu, Y.; Feng, A.; Thang, S.H. Degradable pH and redox dual responsive nanoparticles for efficient covalent drug delivery. Polym. Chem. 2019, 10, 1291-1298. [CrossRef]

20. Lee, M.H.; Yang, Z.; Lim, C.W.; Lee, Y.H.; Dongbang, S.; Kang, C.; Kim, J.S. Disulfide-Cleavage-Triggered Chemosensors and Their Biological Applications. Chem. Rev. 2013, 113, 5071-5109. [CrossRef]

21. Chen, H.; Liu, C.; Xia, Y. One-step synthesis of boronic acid functionalized gold nanoclusters for photoluminescence sensing of dopamine. Methods Appl. Fluoresc. 2017, 5, 014006. [CrossRef] [PubMed]

22. Reckmeier, C.J.; Schneider, J.; Xiong, Y.; Häusler, J.; Kasák, P.; Schnick, W.; Rogach, A.L. Aggregated Molecular Fluorophores in the Ammonothermal Synthesis of Carbon Dots. Chem. Mater. 2017, 29, 10352-10361. [CrossRef]

23. Choi, C.A.; Mazrad, Z.A.I.; Lee, G.; In, I.; Lee, K.D.; Park, S.Y. Boronate-based fluorescent carbon dot for rapid and selectively bacterial sensing by luminescence off/on system. J. Pharm. Biomed. Anal. 2018, 159, 1-10. [CrossRef] [PubMed]

24. Choi, C.A.; Ryplida, B.; In, I.; Park, S.Y. Selective redox-responsive theragnosis nanocarrier for breast tumor cells mediated by $\mathrm{MnO}_{2}$ /fluorescent carbon nanogel. Eur. J. Pharm. Sci. 2019, 134, 256-265. [CrossRef] 
25. Zhao, L.; Zhao, L.; Miao, Y.; Liu, C.; Zhang, C. Construction of a Turn Off-On-Off Fluorescent System Based on Competitive Coordination of $\mathrm{Cu}^{2+}$ between 6,7-Dihydroxycoumarin and Pyrophosphate Ion for Sensitive Assay of Pyrophosphatase Activity. J. Anal. Methods Chem. 2016, 2016, 1-10.

26. Mazrad, Z.A.I.; Lee, K.; Chae, A.; In, I.; Lee, H.; Park, S.Y. Progress in internal/external stimuli responsive fluorescent carbon nanoparticles for theranostic and sensing applications. J. Mater. Chem. B 2018, 6, 1149-1178. [CrossRef]

27. Li, Y.; Xiao, W.; Xiao, K.; Berti, L.; Luo, J.; Tseng, H.P.; Fung, G.; Lam, K.S. Well-Defined, Reversible Boronate Crosslinked Nanocarriers for Targeted Drug Delivery in Response to Acidic pH Values and cis -Diols. Angew. Chemie Int. Ed. 2012, 51, 2864-2869. [CrossRef]

28. Choi, C.A.; Lee, J.E.; Mazrad, Z.A.I.; In, I.; Jeong, J.H.; Park, S.Y. Redox- and pH-responsive fluorescent carbon nanoparticles- $\mathrm{MnO}_{2}$-based FRET system for tumor-targeted drug delivery in vivo and in vitro. J. Ind. Eng. Chem. 2018, 63, 208-219. [CrossRef]

29. Wang, J.; Ma, F.; Sun, M. Graphene, hexagonal boron nitride, and their heterostructures: properties and applications. RSC Adv. 2017, 7, 16801-16822. [CrossRef]

30. Huang, S.-J.; Hsu, Z.-R.; Wang, L.-F. Synthesis and characterization of pluronic-block-poly(N,N-dimethylamino2-ethyl methacrylate) pentablock copolymers for drug/gene co-delivery systems. RSC Adv. 2014, 4, 31552-31563. [CrossRef]

31. Sun, L.; Zhang, X.; An, J.; Su, C.; Guo, Q.; Li, C. Boronate ester bond-based core-shell nanocarriers with pH response for anticancer drug delivery. RSC Adv. 2014, 4, 20208-20215. [CrossRef]

32. Wang, X.; Xia, N.; Liu, L. Boronic Acid-Based Approach for Separation and Immobilization of Glycoproteins and Its Application in Sensing. Int. J. Mol. Sci. 2013, 14, 20890-20912. [CrossRef] [PubMed]

33. Yu, B.; Meng, Q.; Hu, H.; Xu, T.; Shen, Y.; Cong, H. Construction of Dimeric Drug-Loaded Polymeric Micelles with High Loading Efficiency for Cancer Therapy. Int. J. Mol. Sci. 2019, 20, 1961. [CrossRef] [PubMed]

34. Basiruddin, S.; Swain, S.K. Phenylboronic acid functionalized reduced graphene oxide based fluorescence nano sensor for glucose sensing. Mater. Sci. Eng. C 2016, 58, 103-109. [CrossRef] [PubMed]

35. Phuong, P.T.M.; Won, H.J.; Oh, Y.J.; Lee, H.S.; Lee, K.D.; Park, S.Y. The chemistry and engineering of mussel-inspired glue matrix for tissue adhesive and hemostatic. J. Ind. Eng. Chem. 2019. [CrossRef]

(C) 2019 by the authors. Licensee MDPI, Basel, Switzerland. This article is an open access article distributed under the terms and conditions of the Creative Commons Attribution (CC BY) license (http://creativecommons.org/licenses/by/4.0/). 